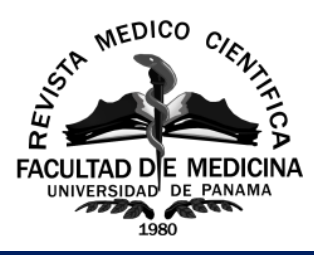

\title{
Los 70 años de fundación de la Facultad de Medicina de la Universidad de Panamá
}

\author{
The $\mathbf{7 0}$ years from foundation of the Faculty of Medicine from the University of Panama
}

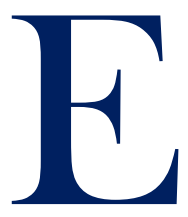

n este 2021 estamos celebrando 70 años de fundación de la Facultad de Medicina. En 1951, ese prohombre de la educación superior panameña, el Dr. Octavio Méndez Pereira, primer Rector de la Universidad, inauguró la Escuela de Medicina para que las hijas y los hijos de los panameños pudieran estudiar medicina en el territorio del istmo. Sus hermanos, Alejandro Méndez Pereira y Gustavo Méndez Pereira lo ayudaron a construir esta Escuela que en poco tiempo llegaría a ser la institución de mayor prestigio académico de la República. A lo largo de siete décadas, hemos graduado miles de médicos, centenares de tecnólogos médicos, nutricionistas, licenciados en Radiología, en Salud Ocupacional, técnicos en urgencias médicas, centenares de máster en Salud Pública, másteres en ciencias médicas básicas y los máster y doctores en ciencias clínicas que han hecho aportes importantes en la preservación de la vida y la salud de los panameños. El valor de una institución educativa se expresa por la calidad de sus egresados. Al celebrar siete décadas de nuestra fundación, podemos decir con profundo orgullo que somos la alma máter de la mayoría de los profesionales de la salud panameños. Nuestros egresados han brillado en todos los escenarios clínicos, científicos y académicos del hemisferio occidental. Es por eso que hoy nosotros debemos rendir homenaje y expresar nuestro profundo agradecimiento a los médicos y profesores panameños y extranjeros que hicieron la Facultad de Medicina. Esta Facultad es el producto de la tarea patriótica, de la inteligencia médica y científica de nuestro país. Esta es la obra de la aristocracia académica de la medicina de este país.

Prohombres de la educación médica como: Antonio González Revilla, Jaime de la Guardia, Rodolfo Valentino Young, Gaspar García de Paredes, Ceferino Sánchez, Plinio Valdés, Enero Avilés y Marion de Martín hicieron nuestra Facultad. Gracias a ellos por habernos dado la oportunidad de recibir una educación médica que no tiene nada que envidiarle a la de otras escuelas de medicina. Después de graduarme de médico en la Universidad de Panamá, yo estuve 4 años en Europa y 4 años en los Estados Unidos y siempre sentí que la formación médica que recibí en nuestra Facultad era absolutamente comparable a la de los médicos egresados de las universidades europeas y americanas y debo insistir en expresar nuestro reconocimiento a los profesores fundadores de la Facultad por habernos dado una educación médica de valor hemisférico.

Quisiera destacar un hecho poco conocido; los profesores fundadores de la Escuela de Medicina también fueron los que iniciaron la educación médica de posgrado en nuestro país. El Dr. Antonio González Revilla estableció el Instituto Walter Dundy en el Hospital Santo Tomás e inició la formación de los neurocirujanos de la República. El Dr. Mario 
Rognoni comenzó la formación de los cardiólogos; el Dr. Herrera la formación de los patólogos; el Dr. Conte-Mendoza intervino en la formación de los ginecólogos; el Dr. Jaime de la Guardia, los González Ruíz y otros brillantes cirujanos comenzaron la formación de los cirujanos y el Dr. Gustavo Méndez Pereira y el Dr. Rolando Chanis fueron pioneros en la formación de los internistas. Hoy hay médicos especialistas en todo el país, formados en nuestros hospitales docentes, por la visión de profesores como la Dra. Marisín Villalaz de Arias quien fue Directora de Docencia del Complejo Hospitalario de la Caja del Seguro Social y del Dr. Gaspar García de Paredes quien fue Director de Docencia del Hospital Santo Tomás. Cabe destacar que el Dr. Rafael Sabonge fue el primer Director de Docencia del Complejo Hospitalario de la Caja del Seguro Social.

En septiembre de 1994, en una reunión histórica en la casa del Ex Rector de la Universidad de Panamá, Dr. Gustavo García de Paredes, en la cual participó la Dra. Aida de Rivera, quien en ese momento fue Ministra de Salud designada; y el Dr. Jorge Montalván, ya fallecido, y mi persona propusimos el inicio del internado y las residencias universitarias. En 1995, junto con el Dr. Tomás Owens padre y el Dr. Luis Carlos Jiménez, comenzamos el primer examen de conocimientos médicos generales del concurso de residencias e hicimos el primer concurso nacional de residencias de la historia del país.

En el 2003 logramos aprobar el internado como una Especialización en Medicina Clínica y las residencias, de las especialidades básicas como Maestrías y Doctorados Clínicos. Desde el 2003 hasta el 2021 hemos logrado aprobar 70 programas de Residencias Universitarias, tanto a nivel de la Junta de Facultad como del Consejo Técnico de Salud. Nos hemos convertido en la única Facultad de Medicina del mundo que tiene la responsabilidad académica de todos los programas de residencias médicas de un país.

El principal desafío que enfrentamos, actualmente, es cómo mantener nuestra Facultad al más alto nivel académico en el siglo XXI. ¿Cómo logramos preservar en este siglo lo que edificaron nuestros profesores fundadores en el siglo pasado? La Facultad de Medicina tiene cuatro períodos importantes en su historia. El primer período va desde 1951 a 1969, fue el momento del inicio de la educación médica en nuestro país. El segundo período se extiende desde 1969 a 1990 donde se consolidó la Facultad de Medicina y el tercer período que inicia en 1990 y llega hasta el 2000, fue el período del liderazgo de la Facultad por los egresados de la misma y aun cuando este período continúa estamos inmersos ya en el cuarto momento de nuestra historia cuya tarea patriótica es preservar la educación médica pública a todo lo largo del siglo $X X I$. Es en este cuarto período que tenemos que construir una nueva Facultad de Medicina; ya iniciamos por primera vez en América Latina el programa MD-PhD para formar médicos con el diploma de investigadores científicos. Este es el período en que nuestra Facultad va a reafirmar más que nunca su vocación global e internacional. Los resultados de los últimos exámenes evaluando el conocimiento para poder ingresar al internado y a las residencias médicas, han demostrado que la Facultad de Medicina de la Universidad de Panamá mantiene el liderazgo en la formación de médicos con conocimientos y competencias para poder atender a las panameñas y panameños. En estos exámenes, hechos por la Junta Nacional Examinadora Médica de los Estados Unidos, todos nuestros estudiantes han pasado con los puntajes más altos.

Además, hemos logrado la acreditación internacional de la Escuela de Medicina. Somos la primera Escuela 
de Medicina del país y una de las primeras de América Latina en lograr la acreditación internacional. Vivimos momentos históricos. La Facultad de Medicina es uno de los últimos bastiones académicos de la educación pública de este país. Nosotros no podemos perder la lucha por preservar la Facultad de Medicina en el siglo XXI. Más que nunca tenemos una cita con nuestra historia y nuestro destino para que las hijas y los hijos de los panameños sean los líderes y los dueños de su propio país.

\section{A. UNIVERSIDAD DE PANAMA FACULTAD DE MEDICINA}

En el Cincuentenario de la fundación de Id Asociación de Estudiantes de Medicina

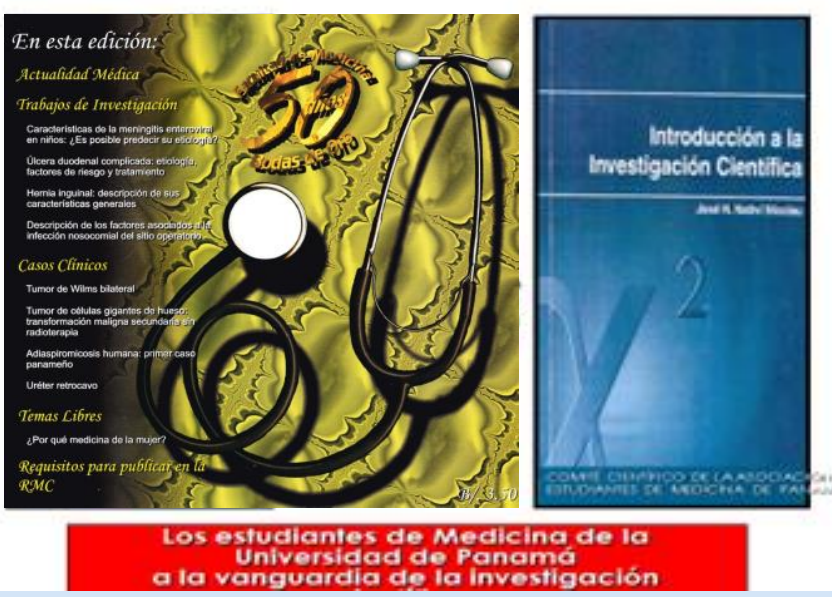

Figura 1. En el cincuentenario de la fundación de la Asociación de Estudiantes de Medicina de Panamá (AEMP)

A la izquierda la edición especial de la Revista Médico Científica en el 2001, celebrando los 50 años de la fundación de la Escuela de Medicina y los 50 años de la fundación de la AEMP. A la derecha el manual de investigación elaborado por el Comité Científico de la AEMP en el año 2000.

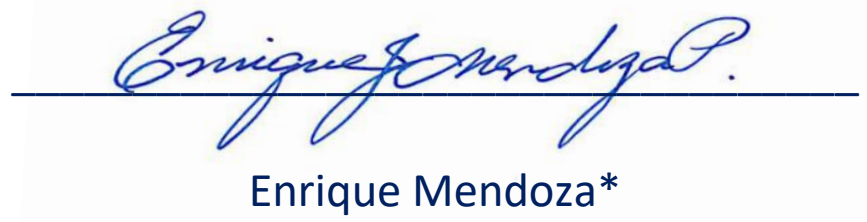

* Decano de la Facultad de Medicina de la Universidad de Panamá. Ex presidente de la AEMP. Ex asesor de la Revista

Médico Científica 